\title{
Effect of human papillomavirus (HPV) vaccination on clinical indicators of sexual behaviour among adolescent girls: the Ontario Grade 8 HPV Vaccine Cohort Study
}

\author{
Leah M. Smith MSc, Jay S. Kaufman PhD, Erin C. Strumpf PhD, Linda E. Lévesque PhD
}

Competing interests: None declared.

This article has been peer reviewed.

Correspondence to:

Leah Smith,

leah.smith3@mail.mcgill.ca

CMAJ 2015. DOI:10.1503 /cmaj.140900

\begin{abstract}
Background: Suboptimal human papillomavirus (HPV) vaccine coverage in some jurisdictions is partly attributed to fears that vaccination may increase risky sexual behaviour. We assessed the effect of HPV vaccination on clinical indicators of sexual behaviour among adolescent girls in Ontario.
\end{abstract}

Methods: Using Ontario's administrative health databases, we identified a population-based cohort of girls in grade 8 in the 2 years before (2005/06 and 2006/07) and after (2007/08 and 2008/09) implementation of Ontario's grade 8 HPV vaccination program. For each girl, we then obtained data on vaccine receipt in grades 8 and 9 and data on indicators of sexual behaviour (pregnancy and non-HPV-related sexually transmitted infections) in grades 10-12. Using a quasi-experimental method known as regression discontinuity, we estimated, for each outcome, the risk difference (RD) and relative risk (RR) attributable to vaccination and to program eligibility.

I nfection with the human papillomavirus (HPV) is the most commonly diagnosed sexually transmitted infection in Canada and around the world. ${ }^{1}$ Although most of these infections are transient and self-resolving, others persist and can cause important health outcomes, including cervical cancer and anogenital warts.

In 2006, Canada was among 49 countries to license Gardasil (Merck, Whitehouse Station, New Jersey), a quadrivalent HPV vaccine designed to protect against 4 types of $\operatorname{HPV}(6,11,16,18)$ that cause $70 \%$ of cases of cervical cancer and most cases of anogenital warts. ${ }^{2-4}$ As one of the first cancer-preventing vaccines, this vaccine received expedited approval in several countries and was the subject of intensive marketing, lobbying and public health campaigns around the world. ${ }^{5}$ By 2012, it had been approved in almost 100 countries, many of which also implemented nationwide HPV vaccination programs aimed primarily at immunizing young girls before the onset of sexual activity. ${ }^{6}$
Results: The cohort comprised 260493 girls, of whom 131781 were ineligible for the program and 128712 were eligible. We identified 15441 (5.9\%) cases of pregnancy and sexually transmitted infection and found no evidence that vaccination increased the risk of this composite outcome: RD per 1000 girls -0.61 (95\% confidence interval [Cl] -10.71 to 9.49) and RR 0.96 (95\% Cl 0.81 to 1.14). Similarly, we found no discernible effect of program eligibility: RD per 1000 girls $-0.25(95 \% \mathrm{Cl}$ -4.35 to 3.85 ) and RR 0.99 ( $95 \% \mathrm{Cl} 0.93$ to 1.06 ). The findings were similar when outcomes were assessed separately.

Interpretation: We present strong evidence that HPV vaccination does not have any significant effect on clinical indicators of sexual behaviour among adolescent girls. These results suggest that concerns over increased promiscuity following HPV vaccination are unwarranted and should not deter from vaccinating at a young age.
Despite the popularity of large-scale immunization programs, HPV vaccination has faced a great deal of controversy regarding unanswered questions about the real-world effects of this vaccine. ${ }^{7,8}$ A major topic of public debate has been the possibility that HPV vaccination might lead to sexual disinhibition, ${ }^{9}$ that is, that receipt of the vaccine might give women and girls a false sense of protection against all sexually transmitted infections and that this false sense of protection might lead them to engage in more risky sexual behaviours than they would otherwise (e.g., be more promiscuous or neglect to use condoms). Increases in these risky behaviours could have important clinical consequences, including increased risk of pregnancy and sexually transmitted infections. Although there is little empirical support for the notion that sexual health interventions promote risky sexual behaviours, ${ }^{10,11}$ this possible unintended effect of the HPV vaccine would undermine its value for 
reducing the burden of sexual health-related diseases. Moreover, parental fears of increased promiscuity following HPV vaccination have been reported as a major determinant of vaccine refusal ${ }^{12}$ which may help to explain suboptimal HPV vaccine coverage in some jurisdictions. ${ }^{6,13}$ Evidently, both actual and perceived sexual disinhibition can have a negative effect on the potential health benefits of HPV vaccination. Therefore, we conducted a population-based, retrospective cohort study to assess the effect of HPV vaccination on clinical indicators of sexual behaviour among adolescent girls in Ontario.

\section{Methods}

This study was based in Ontario, Canada, which began offering all 3 doses of the quadrivalent HPV vaccine to grade 8 girls in September 2007, primarily through school-based clinics. ${ }^{14}$ At that time, girls who were not eligible for the publicly funded program (e.g., in grade 8 before 2007) were able to receive the 3-dose series from their physician or local public health agency at a cost of about $\$ 400$.

To carry out this study, we used 6 of Ontario's population-based administrative databases housed at the Institute for Clinical Evaluative Sciences. These databases, which are described in detail elsewhere (see Appendix 1, available at www.cmaj.ca/lookup/suppl/doi:10.1503/cmaj $.140900 /-/ D C 1),{ }^{15,16}$ were used to obtain individual-level information on sociodemographic characteristics, fee-for-service claims by physicians, hospital admissions, emergency department visits, same-day surgeries and vaccinations. Because each individual in these databases is represented by a unique identifier, anonymized, individual-level linkage of records across databases was possible.

Using these data, we identified a populationbased cohort of all girls eligible for Ontario's grade $8 \mathrm{HPV}$ vaccination program in the first 2 school years it was offered (i.e., 2007/08 and 2008/09). For the purpose of comparison, we also included girls who were in grade 8 in Ontario in the 2 years before the program began (i.e., 2005/06 and 2006/07), who were ineligible for publicly funded, school-based HPV vaccination. We did not have a direct measure of school grade; however, an estimated $96 \%$ of girls enter grade 8 at 13 years after their birth year, ${ }^{17}$ so we identified all females born in 1992, 1993, 1994 and 1995 (to correspond with grade 8 years of 2005/06, 2006/07, 2007/08 and 2008/09, respectively) who were residing in Ontario on Sept. 1 of grade 8 (cohort entry) and whose vaccination records were available at the time of analysis. Cohort members were followed until the earliest of their date of death, occurrence of a study outcome or Mar. 31 of grade 12. To describe this cohort, we identified a number of baseline characteristics relating to sociodemographic characteristics, vaccination history, health service use and medical history.

For this comparison, we used the regression discontinuity design, a quasi-experimental method for assessing the causal effects of policy interventions in a way that accounts for observed and unobserved confounding. ${ }^{18-20}$ Given the analogies between regression discontinuity design and randomization and the advantages it offers over standard regression adjustment, the regression discontinuity design is increasingly used in epidemiology to facilitate reliable causal inference in observational settings. ${ }^{21,22}$ Here, we used the regression discontinuity design to exploit the quasi-experimental situation that arose because girls were "assigned" to Ontario's HPV vaccination program according to whether they were in grade 8 before or after program implementation (i.e., born Dec. 31, 1993, or earlier v. born Jan. 1, 1994, or later), which caused the probability of receiving the vaccine to jump discontinuously between eligibility groups at the eligibility cut-off (see Appendix 2, available at www.cmaj.ca /lookup/suppl/doi:10.1503/cmaj.140900/-/DC1). In this way, the factor influencing exposure to the intervention (known as the "forcing variable") was birth date. In the regression discontinuity design, a corresponding discontinuity in the risk of the outcome at the eligibility cut-off would reflect the causal effect of the intervention, whereas continuity would be suggestive of a null effect (Appendix 2).

Because the forcing variable in this study was based on birth date, the dates of Dec. 31, 1993, and Jan. 1, 1994, defined either side of the eligibility cut-off, and cohort members with birth dates earlier and later than these dates were represented with increasing distance from the cut-off on the ineligible and eligible sides, respectively. For the analyses, the forcing variable was collapsed into 3-month intervals, referred to as "birth year quarters" (Appendix 3, available at www.cmaj.ca /lookup/suppl/doi:10.1503/cmaj.140900/-/DC1).

Our primary outcome was a composite measure of incident pregnancy and non-HPV-related sexually transmitted infections occurring between Sept. 1 of grade 10 and Mar. 31 of grade 12 (Appendix 4, available at www.cmaj.ca/lookup /suppl/doi:10.1503/cmaj.140900/-/DC1). We also assessed each of these 2 clinical indicators of sexual behaviour separately. Cases were "incident" if they occurred following an event-free period of at least 365 days.

To evaluate the program's effects, we used linear regression to model the association between program eligibility and outcomes. In this analysis, 
exposure was defined on the basis of program eligibility, which thus provided an "intention-totreat" estimate of vaccination. To evaluate the effect of the vaccine, actual receipt of vaccine was also taken into account; this was defined as receipt of all 3 doses between cohort entry and Aug. 31 of grade 9 . In this analysis, we used 2-stage linear regression to estimate the association between program eligibility and vaccine exposure, in addition to the association between program eligibility and outcome. Analogously, we applied 1- and 2-stage log-binomial regressions to estimate the relative effect of program eligibility and vaccination on the outcomes. In all analyses, cohort members born in 1993 and 1994 were weighted twice as heavily as those born in 1992 and 1995 because individuals closest to the cut-off are the most comparable. Moreover, analyses were conditioned on birth timing (i.e., birth quarter) because we

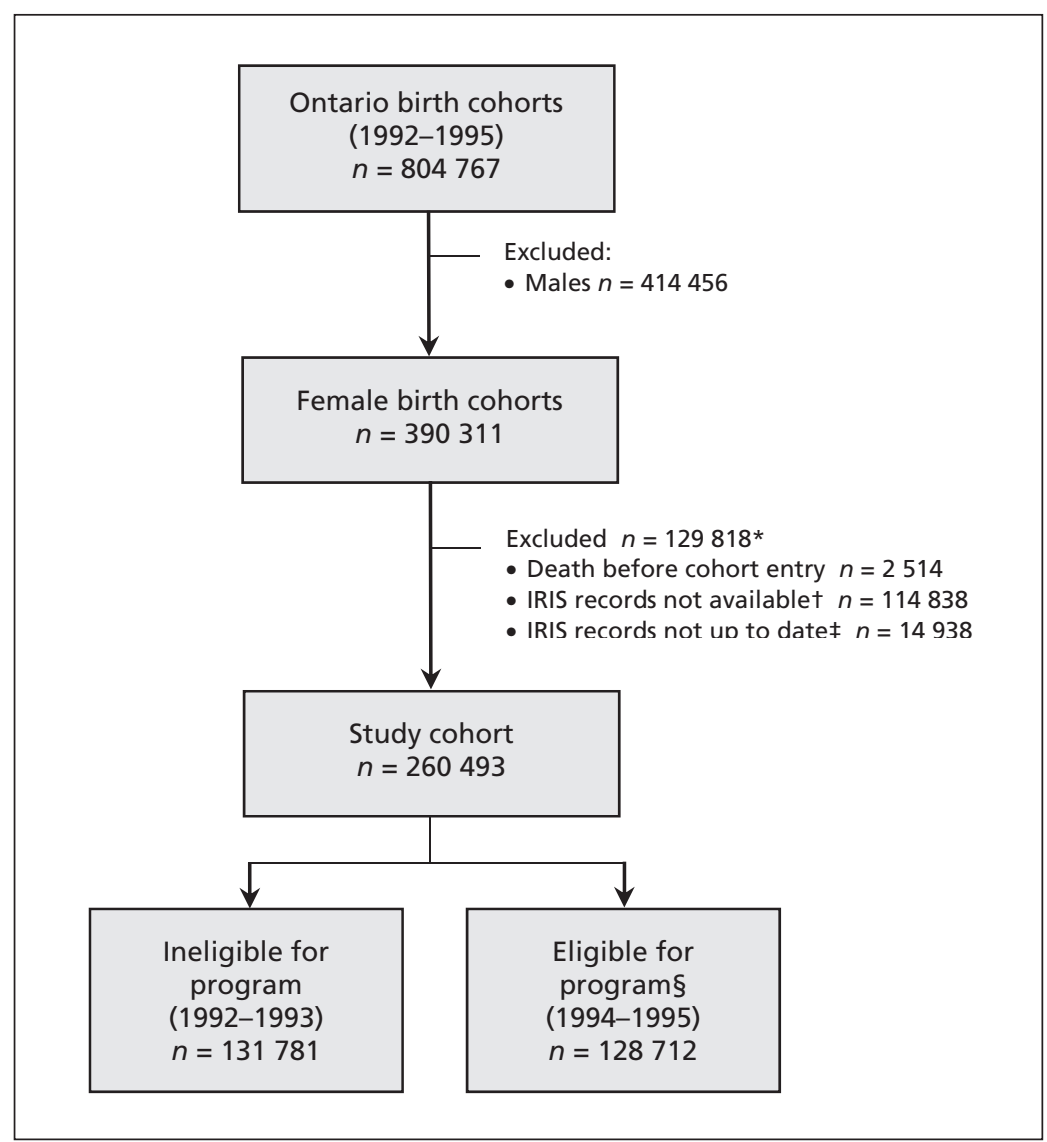

Figure 1: Cohort flow diagram. *The total number of exclusions at this stage is less than the sum of exclusions listed because some girls were excluded for more than one reason. tAt the time of this study, 2 of Ontario's 36 Immunization Records Information System (IRIS) databases, representing about $22 \%$ of Ontario's population, had not yet been transferred to the Institute for Clinical Evaluative Sciences and were therefore unavailable for use. IRIS records were also unavailable for girls who emigrated from Ontario before starting kindergarten or immigrated to Ontario after completing high school. ¥A girl's IRIS record was defined as "up to date" if it had been modified 30 days before cohort entry or later. Otherwise, it was assumed that the girl had moved out of our study area before cohort entry. §Eligible for Ontario's publicly funded, school-based human papillomavirus vaccination program. found that participants born early (or late) in the year were the most comparable across birth years (Appendix 5, available at www.cmaj.ca/lookup /suppl/doi:10.1503/cmaj.140900/-/DC1). We executed sensitivity analyses to test the robustness of our results.

This study was approved by the Institutional Review Board of McGill University's Faculty of Medicine, as well as by the Health Sciences Research Ethics Board of Queen's University. Data management was carried out using SAS statistical software, version 9.3 (SAS Institute Inc., Cary, North Carolina), and statistical analyses were executed using Stata version 13.1 (StataCorp, College Station, Texas). An expanded description of the methods used for this study is presented in Appendix 6 (available at www.cmaj.ca/lookup /suppl/doi:10.1503/cmaj.140900/-/DC1).

\section{Results}

We identified a cohort of 260493 girls, $49.4 \%$ of whom were eligible for publicly funded HPV vaccination (Figure 1). The mean age at cohort entry was 13.17 (standard deviation 0.28 ) years, and cohort members were followed for an average of 4.5 (standard deviation 0.3 ) years. Eligible and ineligible groups were similar, with the possible exception of small differences in neighbourhood income quintile, hepatitis B vaccination history and prevalence of some medical conditions (Table 1).

Although only $51 \%$ of eligible girls received all 3 doses of the HPV vaccine in grades 8 and 9, less than $1 \%$ of ineligible girls received the 3 -dose series, which resulted in a clear discontinuity in HPV vaccine exposure at the eligibility cut-off (Figure 2). About 6\% of cohort members had an outcome of interest between Sept. 1 of grade 10 and Mar. 31 of grade 12, 10187 with pregnancies and 6259 with a non-HPV-related sexually transmitted infection (Table 2). Figure 3, which depicts these risks by birth year quarter, shows that girls born during the first quarter of each year (January-March) were consistently at higher risk of these outcomes than girls born later in the year, which indicates the importance of controlling for birth timing in the analyses. Indeed, we observed no statistically significant increase in risk of the composite measure of indicators of sexual behaviour in relation to HPV vaccination, as evidenced on both the absolute and relative scales: risk difference (RD) per 1000 girls -0.61 (95\% confidence interval $[\mathrm{CI}]-10.71$ to 9.49$)$ and relative risk (RR) 0.96 (95\% CI 0.81 to 1.14 ). In addition, we identified no discernible effect of program eligibility: RD per 1000 girls -0.25 (95\% CI -4.35 to 3.85$)$ and RR 0.99 (95\% CI 0.93 to 1.06). The 
findings were similar when pregnancy and nonHPV-related sexually transmitted infections were assessed separately (Table 3 ). These results were robust to sensitivity analyses.

\section{Interpretation}

In this large population-based cohort study, we found no evidence that publicly funded HPV vaccination had any significant effect on clinical indicators of sexual behaviour. In particular, we found that neither HPV vaccination nor program eligibility increased the risk of pregnancy and non-HPV-related sexually transmitted infections among females aged 14-17 years.

To date, only one other study has reported on the association between HPV vaccination and clinical indicators of risky sexual behaviour. Bednarczyk and colleagues ${ }^{23}$ compared sexual behaviour-related outcomes between vaccinated

Table 1: Baseline characteristics of the eligibility groups in the study cohort

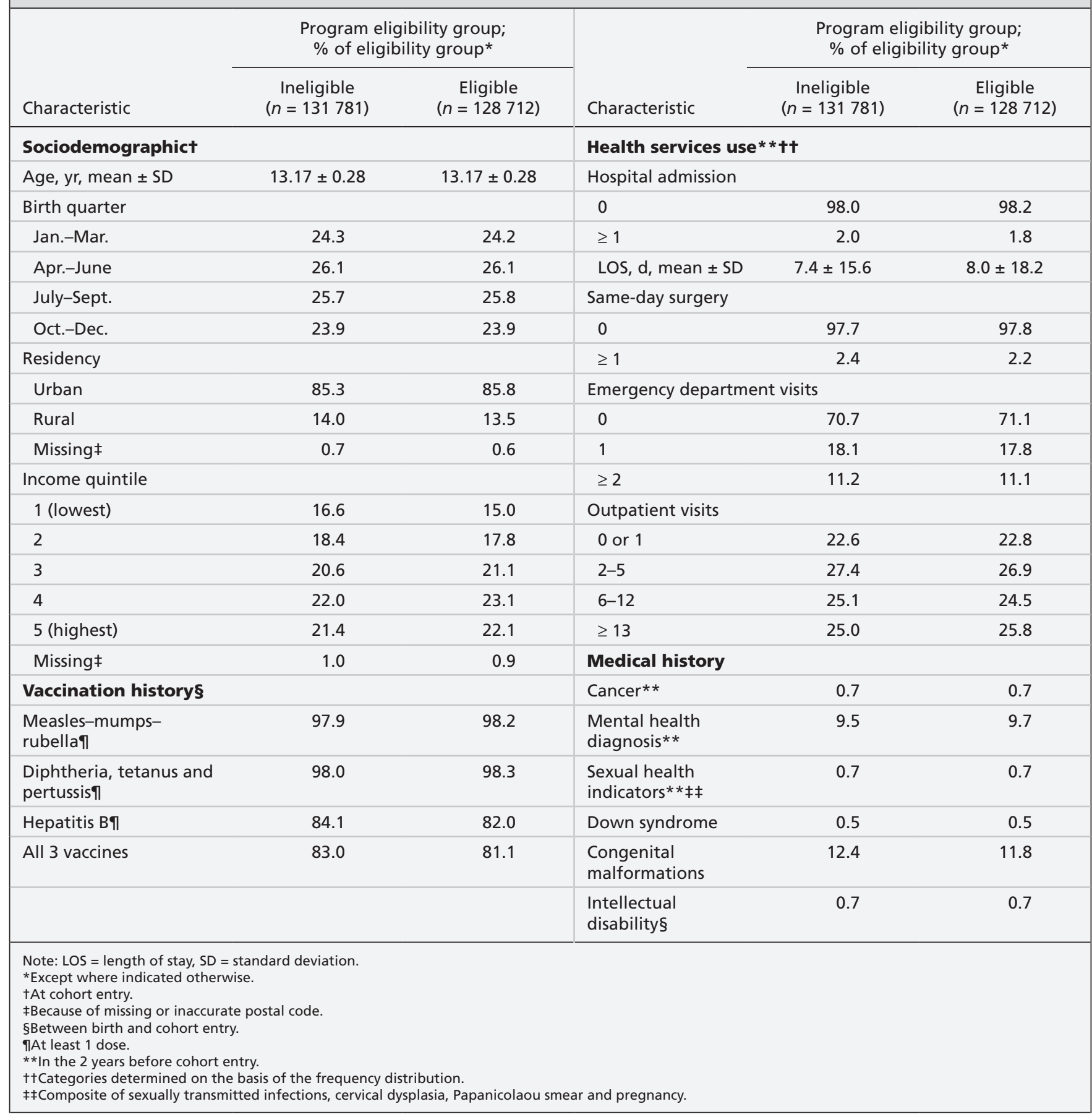


and unvaccinated females and reported that HPV vaccination was not associated with these outcomes (RD 1.6 per 100 person-years, 95\% CI -0.03 to 3.24 ; RR 1.29 , 95\% CI 0.92 to 1.80 ). Their article has been frequently cited as evidence of a lack of association between HPV vaccination and risky sexual behaviours. However, their study was limited by a small sample size ( $n$ $=1398$ ), which is especially important given that the point estimates were suggestive of a potential increased risk. Moreover, because their study directly compared vaccinated and unvaccinated females, the results may have been confounded by health beliefs and behaviours affecting the probability of both the outcome and vaccination.

The few additional studies on this topic have focused on perceptions of risk following vaccination, rather than actual risk, ${ }^{24,25}$ or have relied

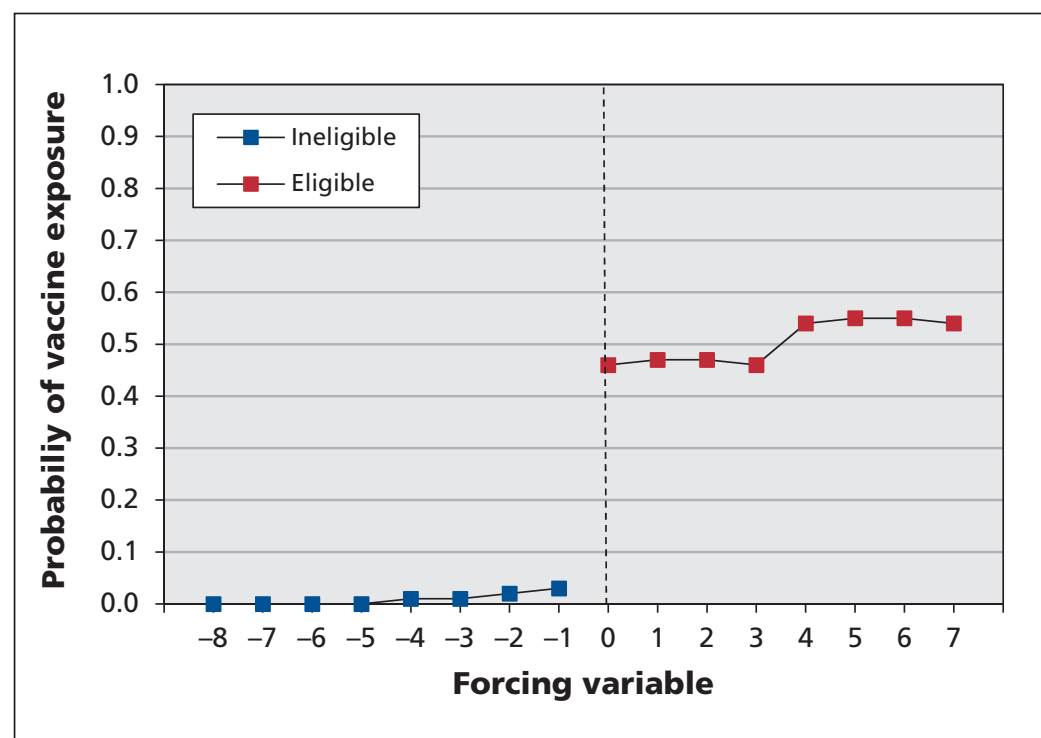

Figure 2: Probability of exposure to the quadrivalent human papillomavirus vaccine according to birth year quarter (the forcing variable) and program eligibility. See Appendix 3 (available at www.cmaj.ca/lookup/suppl/doi:10 $.1503 / \mathrm{cmaj} .140900 /-/ D C 1)$ for a description of how the forcing variable was operationalized. on self-reports of sexual behaviour, ${ }^{26,27}$ which are vulnerable to recall, response and social desirability biases. ${ }^{28,29}$ Furthermore, all were based on small samples (range 193-1243 females). Our study, which was based on a sample of 260493 girls, provides strong evidence against a meaningful risk increase. Our findings are also consistent with studies assessing the effect of school-based sexual health interventions on adolescents' behaviour, which have indicated that programs aimed at improving access to condoms and sexual health education for teens do not increase sexual activity.

A major strength of our study was the use of a methodologic approach that enabled us to avoid the potential for confounding bias that arises when vaccinated and unvaccinated individuals are directly compared. ${ }^{30,31}$ Circumventing this type of bias is particularly important when studying factors related to risky sexual behaviour, because these outcomes are likely strongly associated with the same unmeasured and unidentifiable health beliefs and behaviours that influence HPV vaccine decision-making. ${ }^{12,32,33}$ Theoretically, residual confounding could have arisen in the presence of an intervention that differentially affected eligibility groups, such as a sexual health education program being paired with the HPV vaccination program. However, no such program was implemented in Ontario and, to the best of our knowledge, any sex education provided through the Ontario school system was offered similarly across birth cohorts. Another advantage of using the regression discontinuity design is that it permits assessment of the population-level effect of the vaccination program (i.e., the intention-to-treat effect), in addition to the effect of receiving the vaccine. The consistency of our results between these 2 measures provides additional support for our conclusions. Finally, our study benefited from validated HPV vaccination data, ${ }^{17}$ which minimized the potential for exposure misclassification.

Table 2: Cumulative risk of outcomes, according to eligibility for Ontario's quadrivalent human papillomavirus vaccination program and birth year

\begin{tabular}{|c|c|c|c|c|c|}
\hline \multirow[b]{3}{*}{$\begin{array}{l}\text { Clinical indicator } \\
\text { of sexual behaviour }\end{array}$} & \multicolumn{4}{|c|}{ Program eligibility; birth year; no. (\%) of participants } & \multirow[b]{3}{*}{$\begin{array}{c}\text { Total } \\
(n=260493)\end{array}$} \\
\hline & \multicolumn{2}{|c|}{ Ineligible } & \multicolumn{2}{|c|}{ Eligible } & \\
\hline & $\begin{array}{c}1992 \\
(n=66653)\end{array}$ & $\begin{array}{c}1993 \\
(n=65128)\end{array}$ & $\begin{array}{c}1994 \\
(n=64818)\end{array}$ & $\begin{array}{c}1995 \\
(n=63894)\end{array}$ & \\
\hline Composite outcome & $4203(6.3)$ & $4032(6.2)$ & $3801(5.9)$ & $3405(5.3)$ & 15441 * (5.9) \\
\hline Pregnancy & $2854(4.3)$ & $2658(4.1)$ & $2476(3.8)$ & $2199(3.4)$ & $10187 \quad(3.9)$ \\
\hline STIS & $1609(2.4)$ & $1653(2.5)$ & $1541(2.4)$ & $1456(2.3)$ & $6259 \quad(2.4)$ \\
\hline
\end{tabular}




\section{Limitations}

One limitation of our study is the lack of validation of our outcome measures. Importantly, although we did not intend to capture anogenital warts in our definition of non-HPV-related sexually transmitted infections, it is likely that some cases of anogenital warts were coded as "other venereal diseases." Given that both the vaccine and the HPV vaccination program are intended to reduce the risk of anogenital warts, and given that such reductions have been reported for other jurisdictions, ${ }^{34,35}$ this misclassification would explain why our point estimates for this outcome were slightly below the null. Consequently, we believe that pregnancy is the more valid indicator of sexual behaviour.

A second limitation is the likelihood of underascertainment of our outcomes (e.g., not all pregnancies reported to physicians). Consequently, the absolute risk estimates reported here are likely underestimates, and the risk differences are likely biased toward the null. However, such underascertainment would have affected eligible and ineligible groups equally, and so would not have affected our relative estimates.

Also, we did not have the direct measures of sexual behaviour (e.g., number of sexual partners, condom use) that have been the focus of public controversy. Instead, we used pregnancy and sexually transmitted infections, as these outcomes represent direct measures of the health consequences of risky sexual behaviour. Although these outcomes do not encompass all facets of disinhibition, they are nonetheless objective measures of certain manifestations of risky sexual behaviour that are not susceptible to the biases that affect more direct measures. ${ }^{24,25}$ Moreover, from a public health perspective, changes in rates of pregnancy and sexually transmitted infections are arguably of equal, if not greater, importance, given their direct effect on the health of adolescents and the use of health care services.

Finally, the generalizability of our results to other populations and jurisdictions is not yet known. However, the consistency of our findings with the existing evidence provides support for the absence of sexual disinhibition following HPV vaccination in a range of populations.

\section{Conclusion}

In this large, population-based cohort study, we found strong evidence that HPV vaccination does not have any significant effect on clinical indicators of risky sexual behaviour among adolescent girls. These findings suggest that fears of increased risky sexual behaviour following HPV vaccination are unwarranted and should not be a
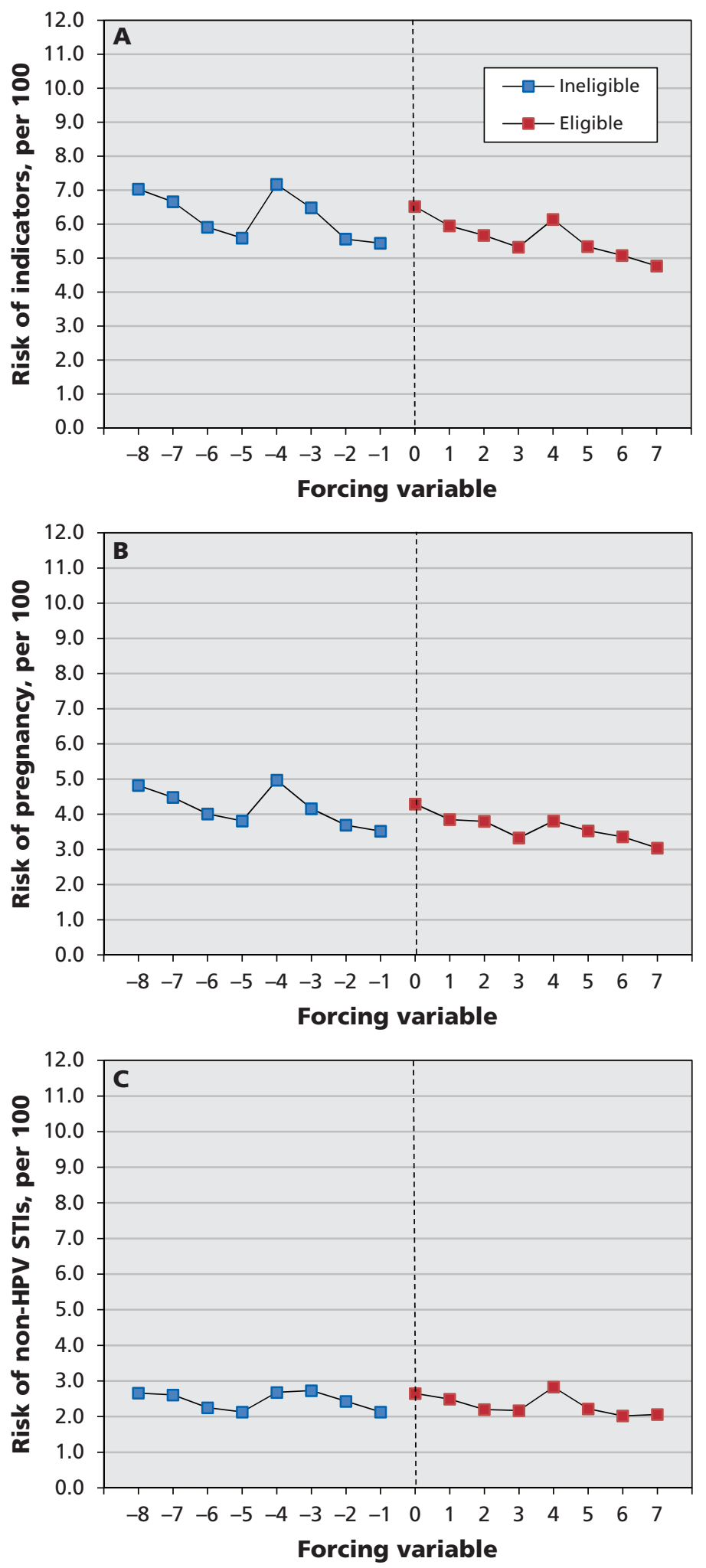

Figure 3: Risk of clinical indicators of sexual behaviour (ascertained for the period between Sept. 1 of grade 10 and Mar. 31 of grade 12), according to birth year quarter (the forcing variable) and eligibility for the human papillomavirus (HPV) vaccination program. (A) Composite outcome of pregnancy and non-HPV-related sexually transmitted infections (STIs). (B) Pregnancy. (C) NonHPV-related STIs. See Appendix 3 (available at www.cmaj.ca/lookup/suppl /doi:10.1503/cmaj.140900/-/DC1) for a description of how the forcing variable was operationalized. 
Table 3: Effect of quadrivalent human papillomavirus vaccination on clinical indicators of sexual behaviour*

\begin{tabular}{|c|c|c|c|}
\hline Outcome & $\begin{array}{l}\text { No. of excess cases per } \\
1000 \text { girls }(95 \% \mathrm{Cl})\end{array}$ & $\mathrm{RR}(95 \% \mathrm{Cl})$ & $\begin{array}{l}\text { Adjusted } \mathrm{RR} \\
\quad(95 \% \mathrm{Cl})\end{array}$ \\
\hline \multicolumn{4}{|l|}{ Effect of vaccine } \\
\hline Composite outcome & $-0.61(-10.71$ to 9.49$)$ & 0.96 (0.81 to 1.14$)$ & 0.98 (0.84 to 1.14$)$ \\
\hline Pregnancy & $0.70 \quad(-7.57$ to 8.97$)$ & 0.99 (0.79 to 1.23$)$ & $1.00(0.83$ to 1.21$)$ \\
\hline STIs & $-4.92(-11.49$ to 1.65$)$ & 0.81 (0.62 to 1.05$)$ & 0.81 (0.63 to 1.04$)$ \\
\hline \multicolumn{4}{|l|}{ Effect of program } \\
\hline Composite outcome & $-0.25 \quad(-4.35$ to 3.85$)$ & 0.99 (0.93 to 1.06$)$ & 1.00 (0.93 to 1.07$)$ \\
\hline Pregnancy & $0.29 \quad(-3.07$ to 3.64$)$ & 1.00 (0.92 to 1.09$)$ & $1.01(0.93$ to 1.10$)$ \\
\hline STIS & $-2.00 \quad(-4.67$ to 0.67$)$ & 0.92 (0.83 to 1.03$)$ & 0.92 (0.83 to 1.03$)$ \\
\hline \multicolumn{4}{|c|}{$\begin{array}{l}\text { Note: } \mathrm{Cl}=\text { confidence interval, } \mathrm{RR}=\text { relative risk, STIs = sexually transmitted infections. } \\
\text { *To address the effect of birth timing that we observed, we used the entire bandwidth of data (i.e., all observations in the } 1992 \\
\text { to } 1995 \text { birth cohorts) and included birth quarter as a covariate in the model. In all analyses, the birth cohorts closest to the } \\
\text { cut-off (1993 and 1994) were weighted twice as heavily as those furthest from the cut-off (1992 and 1995). } \\
\text { tIn this sensitivity analysis, we adjusted for neighbourhood income quintile, hepatitis B vaccination and history of sexual } \\
\text { health-related indictor, as well as for birth quarter. }\end{array}$} \\
\hline
\end{tabular}

barrier to vaccinating at a young age. The results of this study can be used by physicians, public health providers and policy-makers to address public and parental concerns about HPV vaccination and promiscuity.

\section{References}

1. Trottier H, Franco EL. The epidemiology of genital human papillomavirus infection. Vaccine 2006;24 Suppl 1:S1-15.

2. Parry J. Vaccinating against cervical cancer. Bull World Health Organ 2007;85:89-90.

3. Muñoz N, Bosch FX, Castellsague X, et al. Against which human papillomavirus types shall we vaccinate and screen? The international perspective. Int J Cancer 2004;111:278-85.

4. Lacey CJ, Lowndes CM, Shah KV. Chapter 4: Burden and management of non-cancerous HPV-related conditions: HPV6/11 disease. Vaccine 2006;24 Suppl 3:S3/35-41.

5. Haas M, Ashton T, Blum K, et al. Drugs, sex, money and power: an HPV vaccine case study. Health Policy 2009; 92:288-95.

6. Markowitz LE, Tsu V, Deeks SL, et al. Human papillomavirus vaccine introduction - the first five years. Vaccine 2012;30 Suppl 5:F139-48.

7. Haug CJ. Human papillomavirus vaccination - reasons for caution. N Engl J Med 2008;359:861-2.

8. Lippman A, Melnychuk R, Shimmin C, et al. Human papillomavirus, vaccines and women's health: questions and cautions. CMAJ 2007; 177:484-7

9. Forster A, Wardle J, Stephenson J, et al. Passport to promiscuity or lifesaver: press coverage of HPV vaccination and risky sexual behavior. J Health Commun 2010;15:205-17.

10. Kirby D. The impact of schools and school programs upon adolescent sexual behavior. J Sex Res 2002;39:27-33.

11. Mueller TE, Gavin LE, Kulkarni A. The association between sex education and youth's engagement in sexual intercourse, age at first intercourse, and birth control use at first sex. $J$ Adolesc Health 2008:42:89-96.

12. Brewer NT, Fazekas KI. Predictors of HPV vaccine acceptability: a theory-informed, systematic review. Prev Med 2007; 45:107-14.

13. Colucci R, Hryniuk W, Savage C. HPV vaccination programs in Canada: Are we hitting the mark? Report card on cancer in Canada. Toronto: Cancer Advocacy Coalition of Canada; 2008. p. 7-10.

14. Ontario's HPV vaccination program. Toronto: Ministry of Health and Long-Term Care; 2013. Available: www.health .gov.on.ca/en/ms/hpv/ (accessed 2014 Mar. 13)

15. ICES data dictionary. Toronto: Institute of Clinical Evaluative Sciences; 2014. Available: https://datadictionary.ices.on.ca /Applications/DataDictionary/Default.aspx (accessed 2014 Mar. 6).

16. Appendix 4: Data sources and population health indicators limit- ations. An appendix to the initial report on public health (2009). Toronto: Ministry of Health and Long-Term Care, Public Health Division; 2009. Available: www.health.gov.on.ca/en /public/publications/pubhealth/init_report/pdfs/appendix4.pdf (accessed 2014 Mar. 6)

17. Smith LM, Lévesque LE, Nasr M, et al. Validity of the Immunization Record Information System (IRIS) database for epidemiologic studies of the human papillomavirus (HPV) vaccine. Can J Clin Pharmacoepidemiol 2010;17:e90-127.

18. Cook TD. "Waiting for life to arrive"': a history of the regression-discontinuity design in psychology, statistics and economics. J Econom 2007;142:636-54.

19. Imbens GW, Lemieux T. Regression discontinuity designs: a guide to practice. J Econom 2008;142:615-35.

20. Lee H, Munk T. Using regression discontinuity design for program evaluation. In: Proceedings of the 2008 Joint Statistical Meeting; 2008 Aug. 3-7; Denver. Alexandria (VA): American Statistical Association; 2008. p. 1675-82. Available: www .amstat.org/sections/srms/proceedings/y2008/Files/301149.pdf (accessed 2014 Oct. 21)

21. Bor J, Moscoe E, Mutevedzi P, et al. Regression discontinuity designs in epidemiology: causal inference without randomized trials. Epidemiology 2014;25:729-37.

22. O'Keeffe AG, Geneletti S, Baio G, et al. Regression discontinuity designs: an approach to the evaluation of treatment efficacy in primary care using observational data. BMJ 2014; 349:g5293.

23. Bednarczyk RA, Davis R, Ault K, et al. Sexual activity-related outcomes after human papillomavirus vaccination of 11- to 12-year-olds. Pediatrics 2012;130:798-805.

24. Mullins TL, Zimet GD, Rosenthal SL, et al. Adolescent perceptions of risk and need for safer sexual behaviors after first human papillomavirus vaccination. Arch Pediatr Adolesc Med 2012;166:82-8.

25. Mather T, McCaffery K, Juraskova I. Does HPV vaccination affect women's attitudes to cervical cancer screening and safe sexual behaviour? Vaccine 2012;30:3196-201.

26. Liddon NC, Leichliter JS, Markowitz LE. Human papillomavirus vaccine and sexual behavior among adolescent and young women. Am J Prev Med 2012;42:44-52.

27. Forster AS, Marlow LA, Stephenson J, et al. Human papillomavirus vaccination and sexual behaviour: cross-sectional and longitudinal surveys conducted in England. Vaccine 2012; 30:4939-44.

28. Fenton KA, Johnson AM, McManus S, et al. Measuring sexual behavior: methodological challenges in survey research. Sex Transm Infect 2001;77:84-92.

29. Clark LR, Brasseux C, Richmond D, et al. Are adolescents accurate in self-report of frequencies of sexually transmitted diseases and pregnancies? J Adolesc Health 1997;21:91-6.

30. Chen RT, Davis RL. RHodes PH. Special methodological issues in pharmacoepidemiology studies of vaccine safety. In: Strom BL, editor. Pharmacoepidemiology. 4th ed. Chichester (UK): John Wiley \& Sons; 2005. p. 455-85. 
31. Nelson JC, Jackson ML, Weiss NS, et al. New strategies are needed to improve the accuracy of influenza vaccine effectiveness estimates among seniors. J Clin Epidemiol 2009;62:687-94.

32. Rosenthal SL, Rupp R, Zimet GD, et al. Uptake of HPV vaccine: demographics, sexual history and values, parenting style, and vaccine attitudes. J Adolesc Health 2008;43:239-45.

33. Kessels SJ, Marshall HS, Watson M, et al. Factors associated with HPV vaccine uptake in teenage girls: a systematic review. Vaccine 2012;30:3546-56.

34. Leval A, Herweijer E, Ploner A, et al. Quadrivalent human papillomavirus vaccine effectiveness: a Swedish national cohort study. J Natl Cancer Inst 2013;105:469-74.

35. Ali H, Donovan B, Wand H, et al. Genital warts in young Australians five years into national human papillomavirus vaccination programme: national surveillance data. BMJ 2013; 346:f2032.

Affiliations: Department of Epidemiology, Biostatistics, and Occupational Health (Smith, Kaufman, Strumpf), McGill University, Montréal, Que.; Department of Public Health Sciences (Lévesque), Queen's University, Kingston, Ont.

Contributors: Leah Smith was involved in acquiring study data, played a major role in the conception, design and interpretation of the study, carried out the statistical analyses and drafted the manuscript. Erin Strumpf and Jay Kaufman played a major role in the conception, design, analysis and interpretation of the study and critically reviewed the manuscript. Linda Lévesque played the principal role in acquiring the study data, played a major role in the conception, design, analysis and interpretation of the study, and critically reviewed the manuscript. All authors were involved in obtaining funding for this study, have given final approval of the manuscript and agree to be accountable for all aspects of the work.

Funding: This study was funded by a grant from the Canadian Institutes of Health Research (CIHR MOP 130339). The funder had no role in the design or conduct of this study; the collection, analysis or interpretation of the data; the preparation, review or approval of the manuscript; or the decision to submit the manuscript for publication.

This study was also supported by the Institute for Clinical Evaluative Sciences (ICES), which is funded by an annual grant from the Ontario Ministry of Health and Long-Term Care (MOHLTC). The opinions, results and conclusions reported in this paper are those of the authors and are independent from the funding sources. No endorsement by ICES or the Ontario MOHLTC is intended or should be inferred.

Leah Smith is supported by a CIHR Fredrick Banting and Charles Best Canada Graduate Scholarships Doctoral Award; Jay Kaufman by the Canada Research Chairs program; Erin Stumpf by a Chercheure Boursier Junior 1 from the Fonds de recherche du Québec-Santé and the Ministère de la Santé et des Services sociaux du Québec; and Linda Lévesque by the Canadian Foundation for Innovation Leaders Opportunity Fund. 